\title{
Study of Mechanism of the W-OH Sand Fixation
}

\author{
Weimin Gao ${ }^{1,2}$, Zhiren $\mathrm{Wu}^{1}$, Zhishen $\mathrm{Wu}^{3^{*}}$ \\ ${ }^{1}$ Jiangsu ATK Environmental Engineering Design and Research Institute Co., Ltd., Wuxi, China; ${ }^{2}$ Jiangsu JCK New Material \\ Technology Co., Ltd., Nanjing, China; ${ }^{3}$ Department of Urban and Civil Engineering, Ibaraki University, Hitachi, Japan. \\ Email: ${ }^{*}$ zswu@mx.ibaraki.ac.jp
}

Received May $9^{\text {th }}, 2012$; revised June $12^{\text {th }}, 2012$; accepted July $17^{\text {th }}, 2012$

\begin{abstract}
A novel hydrophilic polyurethane (abbreviated as $\mathrm{W}-\mathrm{OH}$ ) was developed and applied as a sustainable sand-fixing material. This paper on the chemical sand fixation mechanism of W-OH discusses the adhesive force between the W-OH solid and sand particles. The solidification mechanism was investigated and the solidifying time was tested. And then the thickness and porosity of the W-OH sand-fixing layer were investigated. By scanning electron microscopy (SEM), the microstructure of the W-OH sand-fixing layer was examined. The hardness and compressive stress of the sand-fixing specimens were studied at W-OH different concentrations. Finally, the resistance to wind erosion of the W-OH sand-fixing layer was investigated by a wind tunnel test. The results demonstrated that the $\mathrm{W}-\mathrm{OH}$ aqueous solution had an excellent affinity for water on the surface of the sand particles, and the adhesive force between the W-OH solid and sand was primarily hydrogen bonding, covalent bonds and physical absorption, such as Van Der Waals forces. W-OH is a prepolymer of hydrophilic polyurethane containing groups of -NCO that can quickly react with water and other groups containing active $\mathrm{H}$. The $\mathrm{W}-\mathrm{OH}$ aqueous solution solidified in the range of 2 min to $15 \mathrm{~min}$. The solidifying time decreased with increasing temperature and concentration. Before solidifying it had a good permeability of sand and the formed sand-fixing layer had a thickness of $8-35 \mathrm{~mm}$ and a porosity of $25 \%-8 \%$ at a spraying concentration of 2 $10 \mathrm{~L} / \mathrm{m}^{2}$. The hardness index of the sand-fixing layer was in the range of $21 \mathrm{~mm}$ to $28 \mathrm{~mm}$ and compressive stress was in the range from $0.21 \mathrm{MPa} m$ to $1.27 \mathrm{MPa}$, both of which increased linearly with W-OH concentration. Sand treated by over 3\% W-OH concentrations showed excellent resistance to wind/sand erosion of more than $25 \mathrm{~m} / \mathrm{s}$.
\end{abstract}

Keywords: W-OH Sand Fixation; Adhesive Force; Porosity; Solidifying Time; Wind Tunnel Test

\section{Introduction}

Due to global climate change and intense human activity, land degradation has become a serious problem, particularly in ecologically sensitive arid and semi-arid areas; it is one of the most serious environmental and socioeconomic problems worldwide and a major threat to the sustainability of agriculture and economic development $[1,2]$. Desertification can cause many negative effects: dust storms, damage to crops, spreading of polluted sediments, loss of fertilizer, and the deposition of soil in ditches and trenches [3-6]. Some management measures have already been taken or proposed to decrease or prevent wind erosion. Pebble or gravel mulching can reduce evaporation and runoff, improving infiltration and soil temperature and maintaining soil fertility. Inserting straw in fallow soil can increase soil surface roughness and reduce wind erosion. The surface application of animal slurries or sewage has been suggested to be effective against wind erosion [7-10]. However, these measures

"Corresponding author. have limitations in terms of cost, effectiveness, and convenience for the vast and hostile environmental of the desert [11-13]. Chemical sand fixation was first proposed in the 1930s. With the development of the chemical industry, an increasing number of sand-fixing materials were developed and applied to desert control. They were primarily natural and/or synthetic compounds [14-17]. However, due to the high cost, environmental toxicity, weak resistance to UV degradation, and inhibition of vegetation, most of these materials were developed and studied only in laboratories and were not applied on a large scale.

A novel sand-fixing composite material of hydrophilic polyurethane (abbreviated as $\mathrm{W}-\mathrm{OH}$ ) was used as a sustainable chemical sand-fixing material with water as a solidifying agent. W-OH was prepared by EO/PO copolyethers, excessively modified 4,4'-diphenylmeth-ane di-isocyanate (modified MDI) and other functional materials. A homogeneous $\mathrm{W}-\mathrm{OH}$ aqueous solution was formed by dissolving $\mathrm{W}-\mathrm{OH}$ in water. It then solidified by a cross-linking reaction to form a network structure. 
Because of the low viscosity before solidification, the $\mathrm{W}-\mathrm{OH}$ aqueous solution had excellent sand permeability. Therefore, it can penetrate to reach the inner layers of sand after being sprayed on the sand surface $[18,19]$. According to previous research, $\mathrm{W}-\mathrm{OH}$ has excellent resistance to UV degradation, and the W-OH sand-fixing layer is suitable for plant growth. The technology of desert control based on $\mathrm{W}-\mathrm{OH}$ is a combination of chemical fixation and biological fixation, and it is a latent and effective method for preventing desertification and realizing gradual ecological restoration $[20,21]$.

In this paper, for the development of the chemical sand fixation theory based on $\mathrm{W}-\mathrm{OH}$, the chemical sand fixation mechanism of W-OH was studied. First, the adhesive force between the $\mathrm{W}-\mathrm{OH}$ solid and sand particles was analyzed. Then, the solidification mechanism was considered and tested at temperatures ranging from $5^{\circ} \mathrm{C}$ to $25^{\circ} \mathrm{C}$. By setting the spray amount between $2.5 \mathrm{~L} / \mathrm{m}^{2}$ and $10 \mathrm{~L} / \mathrm{m}^{2}$, the relationship among the amount of sprayed material, thickness and porosity of the $\mathrm{W}-\mathrm{OH}$ sand-fixing layer was also investigated. The microstructure of the W-OH sand-fixing layer was examined by SEM. To evaluate the mechanical properties of the $\mathrm{W}$ $\mathrm{OH}$ sand-fixing layer, the hardness and compressive stress of the treated sand were studied at W-OH concentrations ranging from $3 \%$ to $7 \%$. Finally, the resistance to wind erosion of the W-OH sand-fixing layer was investigated in wind tunnel tests. The wind erosion modulus was measured and studied by setting the wind-sand flow velocity to $10 \mathrm{~m} / \mathrm{s}, 15 \mathrm{~m} / \mathrm{s}, 20 \mathrm{~m} / \mathrm{s}$ or $25 \mathrm{~m} / \mathrm{s}$ and the angle of incidence to $0^{\circ}, 30^{\circ}$ or $60^{\circ}$, respectively.

\section{Experimental}

\subsection{Testing W-OH Solidification Time}

The W-OH aqueous solution was prepared by dissolving self-made $\mathrm{W}-\mathrm{OH}$ in water with concentrations of $3 \%$ $5 \%$. Then, the viscosity of the $\mathrm{W}-\mathrm{OH}$ aqueous solution was tested with a rotational viscometer (HA-AKE VT550), and the solidifying time was recorded. The temperature effect on the $\mathrm{W}-\mathrm{OH}$ solidifying reaction was studied by changing the water temperature in the range of $5^{\circ} \mathrm{C}$ and $25^{\circ} \mathrm{C}$. This reaction is shown in Figure 1.

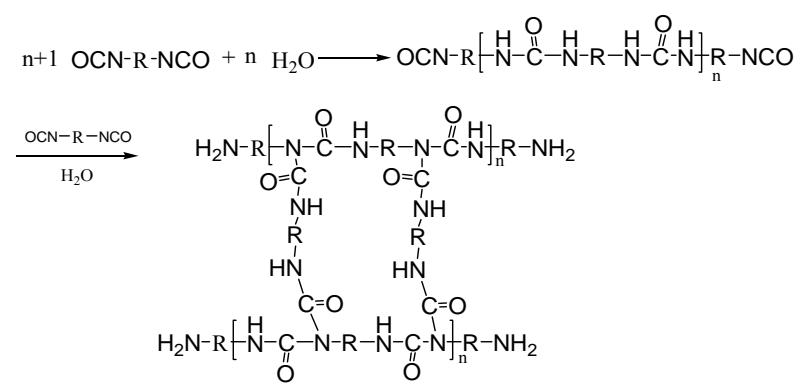

Figure 1. Reaction formula for $\mathrm{W}-\mathrm{OH}$ solidification.

\subsection{Studying the Permeability of the $\mathrm{W}-\mathrm{OH}$ Aqueous Solution}

To determine the permeability of the W-OH aqueous solution, $200 \mathrm{~g}$ of Toyoura sand was placed into a mold ( $5 \mathrm{~cm}$ in diameter and $10 \mathrm{~cm}$ in height), and a $3 \% \mathrm{~W}-\mathrm{OH}$ aqueous solution was sprayed on the sand surface at rates from $2.5 \mathrm{~L} / \mathrm{m}^{2}$ to $10 \mathrm{~L} / \mathrm{m}^{2}$. It immediately penetrated into the inner layers (the grain-size distribution of the sand is shown in Table 1; the dominant components of the sand were the particle sizes between $0.2-0.25 \mathrm{~mm}$ and 0.15 $0.2 \mathrm{~mm}$ with a density of $1.52 \mathrm{~g} / \mathrm{cm}^{3}$ and a porosity of $42.6 \%$ ). Several minutes later, a W-OH sand-fixing layer formed on the sand surface and air dried at room temperature $\left(20^{\circ} \mathrm{C}\right)$ with a relative humidity of $30 \%$ for three weeks. The thickness of the W-OH sand-fixing layer was measured, and the microstructure of the W-OH sandfixing layer was examined by SEM (HitachiS-570).

\subsection{Testing the Mechanical Properties of the W-OH Sand-Fixing Specimen}

To determine the mechanical properties of the W-OH aqueous solution, Toyoura sand was placed into a mold by the same method described in 2.2 , and different concentrations of $\mathrm{W}-\mathrm{OH}$ ranging from $2 \%$ to $7 \%$ were sprayed onto the sand surface. The $\mathrm{W}-\mathrm{OH}$ sand-fixing specimens were formed with a thickness above $50 \mathrm{~mm}$, and, one week later, the specimens were removed from the cylindrical grinding and kept at room temperature for another 28 days. The $\mathrm{W}-\mathrm{OH}$ sand-fixing specimens resulting from the surface treatment were $50 \mathrm{~mm}$ in diameter and $50 \mathrm{~mm}$ in height.

The hardness of the sand-fixing specimen was measured by the Yamanaka-type soil penetrometer. A steel circular cone of the penetrometer was thrust against a sand surface, and the repulsion force of the spring in the penetrometer indicated the hardness index of the W-OH sand-fixing specimen.

To gain clear insight into the mechanical behavior of the $\mathrm{W}-\mathrm{OH}$ sand-fixing specimens, the uniaxial compressive specimens were tested by compressing different concentrations of $\mathrm{W}-\mathrm{OH}$. The concentrations were $3 \%$, $4 \%$ and $5 \%$. The loading was controlled by displacement at a rate of $1 \mathrm{~mm} / \mathrm{min}$ by an electro-hydraulic Servo universal testing machine, using the strain gauge (PL-60-11) to measure the horizontal deformation and the displacement transducer (CDP-50) for measuring the axial displacement. The schematic diagram of the compressive

Table 1. The particle analysis of sand (in weight percent).

\begin{tabular}{ccccc}
\hline \multicolumn{4}{c}{ Grain size distribution $(\mu \mathrm{m})$} \\
\hline$>300$ & $250-300$ & $250-150$ & $150-100$ & $<100$ \\
0.02 & 12.72 & 73.06 & 3.56 & 0.64 \\
\hline
\end{tabular}


experiments is shown in Figure 2.

\subsection{Indoor Wind Tunnel Test of the W-OH Sand-Fixing Specimen [22,23]}

A wind tunnel test was carried out at the Key Laboratory of Desert and Desertification in the Cold and Arid Regions Environmental and Engineering Research Institute, Chinese Academy of Sciences, Lanzhou. The laboratory was built in 1967 and is the largest wind tunnel laboratory in Asia. The wind tunnel has a direct current, is closed and inflatable and runs at a low velocity with a total length of $37.78 \mathrm{~m}$. The length of the testing section is $16.23 \mathrm{~m}$ (Figure 3), the cross-section of the wind tunnel is rectangular with an area of $100 \mathrm{~cm} \times 60 \mathrm{~cm}$, and the walls are smooth and made of multiple layers of plywood and glass. The equipment for the sand supply was set in the front of the wind tunnel, and the wind velocity was adjusted to the range of $2 \mathrm{~m} / \mathrm{s}$ to $40 \mathrm{~m} / \mathrm{s}$ with the turbulence intensity below 0.4 . A pilot-tube and a sand sampler with multiple tubes were used for measuring the wind velocity.

The steps of the wind tunnel test were as follows:

1) A sample of $8000 \mathrm{~g}$ of Toyoura sand was placed into a rectangular sand table with a size of $32 \mathrm{~cm} \times 40$ $\mathrm{cm} \times 4.5 \mathrm{~cm}$, and then the sand surface was flattened.

2) $\mathrm{W}-\mathrm{OH}$ aqueous solutions with concentrations ranging from $2 \%$ to $5 \%$ were prepared by dissolving $\mathrm{W}-\mathrm{OH}$ in water, and the solutions were sprayed on the prepared sand surface at a rate of $3 \mathrm{~L} / \mathrm{m}^{2}$. The aqueous solution penetrated the interior of the sand immediately, and a

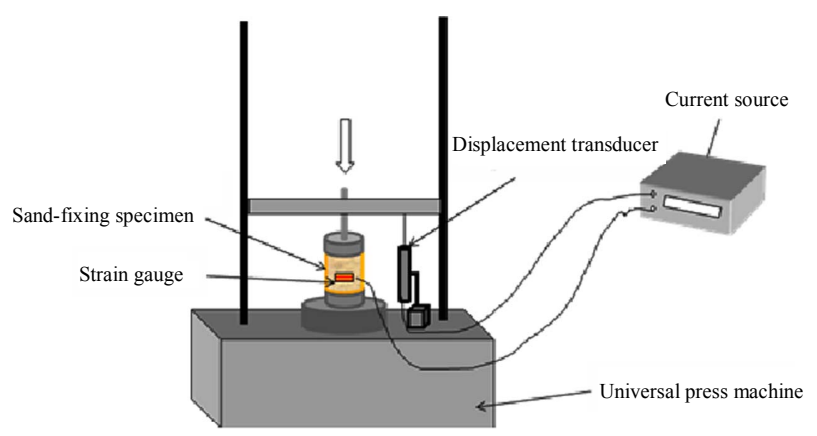

Figure 2. Schematic diagram of compressive experimental.

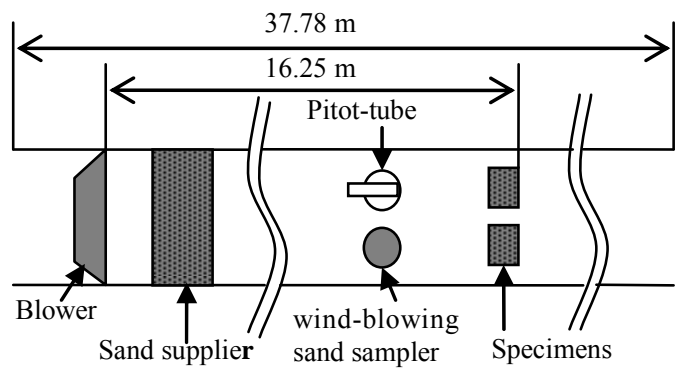

Figure 3. Schematic diagram of wind tunnel. sand-fixing layer formed rapidly as the $\mathrm{W}-\mathrm{OH}$ aqueous solution solidified. The $\mathrm{W}-\mathrm{OH}$ sand-fixing specimens were air dried at room temperature $\left(20^{\circ} \mathrm{C}\right)$ and air humidity of $30 \%$ for one week.

3) The prepared W-OH sand-fixing specimens were placed into the testing section of the wind tunnel and tested under the action of a wind-sand flow with a certain velocity and angle. The velocity was measured and controlled by the pilot-tube, and a sand sampler with multiple tubes was used to measure the sand flow. The testing parameters were set with a wind-sand flow velocity of either $10 \mathrm{~m} / \mathrm{s}$ for $30 \mathrm{~min}, 15 \mathrm{~m} / \mathrm{s}$ for $20 \mathrm{~min}, 20 \mathrm{~m} / \mathrm{s}$ for $10 \mathrm{~min}$ or $25 \mathrm{~m} / \mathrm{s}$ for $8 \mathrm{~min}$ and angles of incidence of $0^{\circ}$, $30^{\circ}$ or $60^{\circ}$, respectively.

\section{Results and Discussion}

\subsection{Analyzing the Adhesive Mechanism between the W-OH Solid and Sand Particles}

Two factors impact the adhesion between the W-OH aqueous solution and the sand. The first is the wettability of the W-OH aqueous solution on the surface of sand particles. It disperses evenly on the sand particle surface, provided the $\mathrm{W}-\mathrm{OH}$ aqueous solution has suitable wettability. The second factor involves polar and reactive groups in the $\mathrm{W}-\mathrm{OH}$ aqueous solution that can adhere to sand by physical and chemical effects to form a strong adhesive force. The relationship among the sand surface tension, the surface tension of the W-OH aqueous solution and the interfacial surface tension is described by Young's equation (Equation (1)).

$$
\gamma_{S}=\gamma_{S L}+\gamma_{L} \cos \theta
$$

where $\theta$ is the wetting angle of $\mathrm{W}-\mathrm{OH}$ aqueous solution on the sand particle surface.

Figure 4 shows the schematic diagram of the W-OH aqueous solution soaking on the surface of the sand particle and the force between the W-OH solid and the sand particles. The W-OH aqueous solution can easily wet the sand surface when $\theta$ is small. To compare the surface tension of the $\mathrm{W}-\mathrm{OH}$ aqueous solution with the sand surface tension, the concept of critical sand surface tension is introduced, which is defined as $\theta$ equals $0^{\circ}$ when the sand surface tension is critical; the relationship between the critical sand surface tension, the surface tension of the $\mathrm{W}-\mathrm{OH}$ aqueous solution, and interface surface tension is shown in Equation (2):

$$
\gamma_{C}=\gamma_{S L}+\gamma_{L}
$$

where $\gamma_{C}$ is the critical sand surface tension. Because $\gamma_{S L}$ is generally small, approaching zero, the

$\lim _{\gamma_{S L \rightarrow 0}} \gamma_{C}=\gamma_{L}$; this means the wettability is best when the surface tension of the $\mathrm{W}-\mathrm{OH}$ aqueous solution is equal to the sand surface tension. 
Because $95 \%$ - $97 \%$ of the $\mathrm{W}-\mathrm{OH}$ aqueous solution is water and because the surface tension of water is very high, there is a high cohesive energy of the urethane bond and urea bond in the W-OH-solidification structure and it can bond to form an adhesive layer of high surface tension. It is well known that sand surface tension is also very high, belonging to a high-energy surface. The wetting angle between the $\mathrm{W}-\mathrm{OH}$ aqueous solution and sand is small, and the surface tension of the $\mathrm{W}-\mathrm{OH}$ aqueous solution is similar to the sand surface tension; therefore, the $\mathrm{W}-\mathrm{OH}$ aqueous solution can soak into and disperse evenly on the sand surface. The procedure for the $\mathrm{W}-\mathrm{OH}$ aqueous-solution dispersion on the sand is shown in Figures 4 (a)-(c).

Soft and hard segments in the structure of the W-OH and $\mathrm{W}-\mathrm{OH}$ solid exhibit thermodynamic incompatibility and micro-phase separation, forming phase regions and micro-phase regions in the matrix. This indicates that the $\mathrm{W}-\mathrm{OH}$ solid has special adhesive properties. Because of the $-\mathrm{NCO}$ and polar groups in the $\mathrm{W}-\mathrm{OH}$ that can react with $\mathrm{H}_{2} \mathrm{O}$ and other groups with active hydrogen, $\mathrm{H}_{2} \mathrm{O}$ and $-\mathrm{OH}$ are distributed on the surface of the sand particles; hydrogen bonds and covalent bonds, such as the urea bond and urethane bond, can form between the sand particles and the $\mathrm{W}-\mathrm{OH}$ solid when the $\mathrm{W}-\mathrm{OH}$ aqueous solution disperses evenly on the surface of sand particles. Figure 4(d) is the schematic diagram of the force between the W-OH solid and the sand. The adhesive force of this system is much greater than that of other sandfixing materials that fix sand by weak physical absorption.
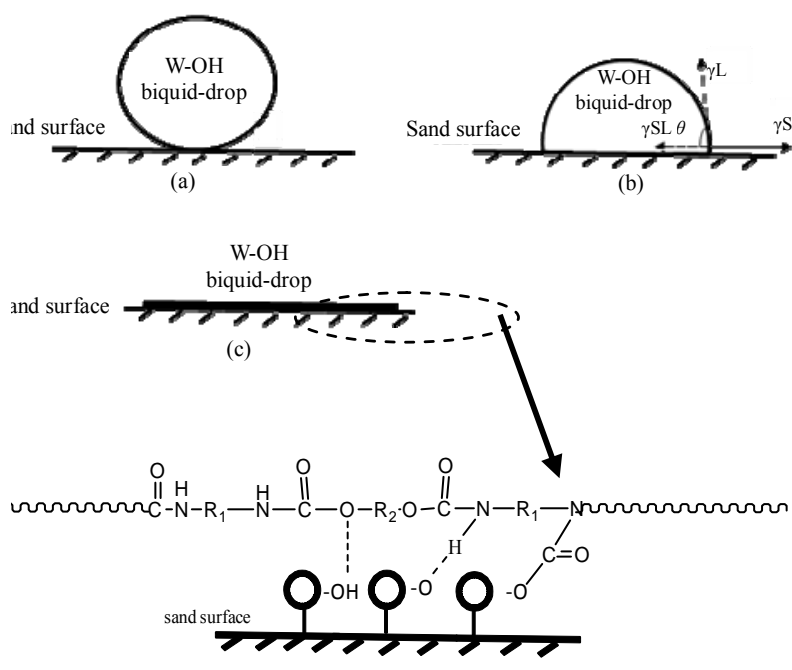

(d)

Figure 4. The mechanism of chemical sand fixation based on $\mathrm{W}-\mathrm{OH}$. (a) The spraying $\mathrm{W}-\mathrm{OH}$ liquid-drop on the sand surface; (b) The dispersion of $\mathrm{W}-\mathrm{OH}$ liquid-drop on the sand surface; (c) The uniformly distributed W-OH liquiddrop on the sand surface; (d) The adhesive mechanism between W-OH solidification and sand.
The schematic diagram of the sand-fixation mechanism based on W-OH is shown in Figure 5. When the $\mathrm{W}-\mathrm{OH}$ aqueous solution is sprayed on the sand surface (Figure 5(a)), it can penetrate though the sand pores and evenly disperse on the surface of the sand particles. In only a few minutes, the $\mathrm{W}-\mathrm{OH}$ aqueous solution solidifies, and the W-OH solid acts as a strong force with the sand, forming a sand-fixing layer with a known stress (Figure 5(b)). With the water evaporation, the volume of the W-OH solid decreases, and the sand contracts (Figure 5(c)). It appears that the $\mathrm{W}-\mathrm{OH}$ solid constructs a bridge between the shifting sand and links the sand together to form a sand-fixing layer with good resistance to high stress and wind erosion, which can provide a suitable and stable environment for planting. As shown in Figure 6, the microstructure of the layer was observed by SEM.

\subsection{Discussing the $\mathrm{W}-\mathrm{OH}$ Solidification Mechanism and Short Solidification Time}

$\mathrm{W}-\mathrm{OH}$ can dissolve in water and emulsify and disperse

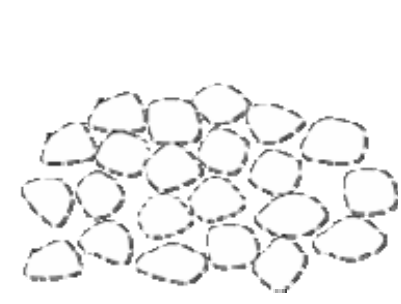

(a)

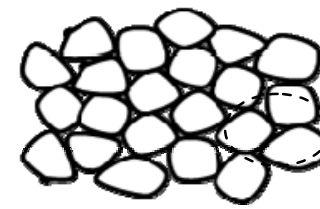

(c)

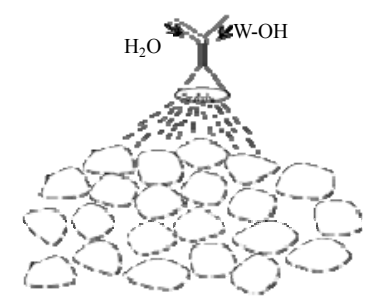

(b)
Figure 5. The procedure of chemical sand fixation based on W-OH. (a) Shifting sand; (b) Spraying W-OH aqueous solution; (c) Fixed sand effected by W-OH solidification.

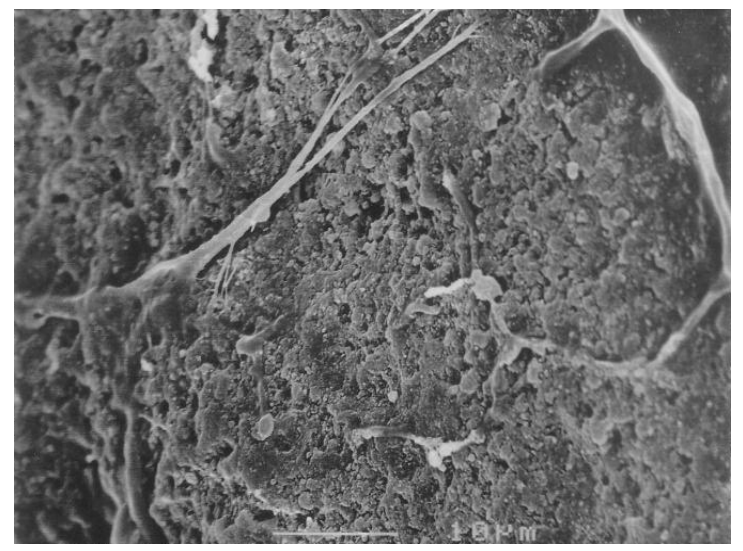

Figure 6. Microstructure of the W-OH sand-fixing layer by SEM. 
homogeneously, forming a W-OH aqueous solution, and then solidify over several minutes. As shown in Figure 2, the mechanism of solidification is initiated by the - $\mathrm{NCO}$ group in W-OH, which reacts with water, and the molecular weight increases sharply by cross-linking. Meanwhile, $\mathrm{CO}_{2}$ is released, and a porous solid is formed. The cross-linking reaction is characterized by high reactivity. When the concentration of $\mathrm{W}-\mathrm{OH}$ is less than $3 \%$, the cross-linking reaction cannot solidify with enough strength due to the low cross-linking density and low molecular weight. Therefore, the $3 \% \mathrm{~W}-\mathrm{OH}$ concentration is necessary for the chemical sand fixation. The relationship between the solidification time of W-OH and the temperature is shown in Figure 7. With the increase in temperature from $5^{\circ} \mathrm{C}$ to $25^{\circ} \mathrm{C}$, the molecular motion accelerates, and the cross-linking reaction velocity increases. However, the cross-linking density decreases, and thus, the strength of the solid also decreases. Comparing the temperatures of $5^{\circ} \mathrm{C}$ and $25^{\circ} \mathrm{C}$, the solidification time decreases by more than $1 / 2$, from $13.8 \mathrm{~min}$ to $6 \mathrm{~min}$ for a concentration of $3 \%$, from $10 \mathrm{~min}$ to $4.3 \mathrm{~min}$ for a concentration of $4 \%$, and from $5.6 \mathrm{~min}$ to $2.4 \mathrm{~min}$ for a concentration of $5 \%$, respectively. When the temperature is higher than $30^{\circ} \mathrm{C}$, W-OH cannot solidify because of the low cross-linking density and molecular weight. The solidification time and strength can be easily regulated by changing the temperature and concentration of $\mathrm{W}-\mathrm{OH}$ according to the application in different environments for the best chemical sand fixation effect.

\subsection{Permeability of the W-OH Aqueous Solution and Porosity of the W-OH Sand-Fixing Layer}

Due to low viscosity before solidification, the W-OH aqueous solution can easily penetrate the sand after being sprayed on the sand surface. Examination of the SEM

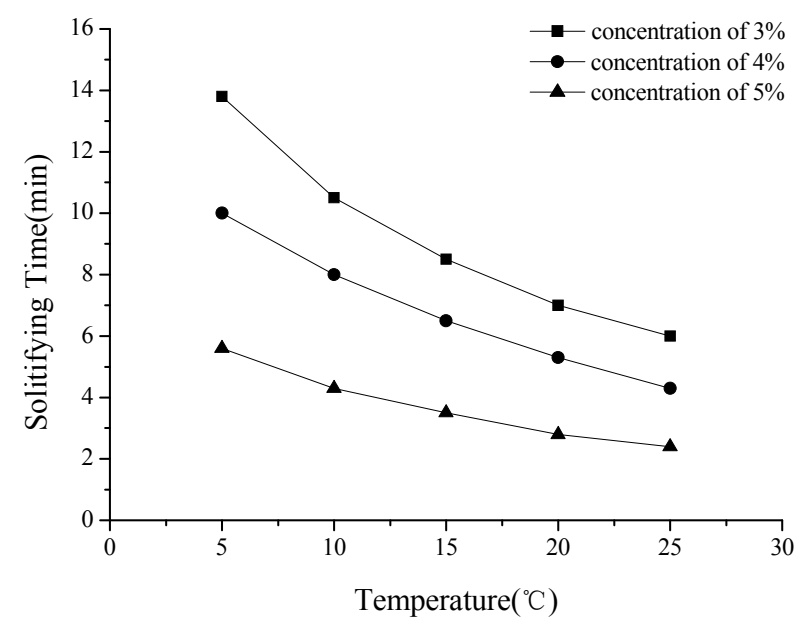

Figure 7. Relationship between W-OH solidifying time and temperature. micrograph of the sand-fixing layer (Figure 6) indicates that the $\mathrm{W}-\mathrm{OH}$ aqueous solution is distributed on the surface of the sand particles and then solidified. The solid is elastic and connects the sand particles one by one. As a result, the shifting sand is fixed, and a sand-fixing layer forms on the sand surface. However, the pores surrounding the sand particles are not fully occupied by the $\mathrm{W}-\mathrm{OH}$ solid, and the sand-fixing layer is characterized by its porosity. The porosity of the sand-fixing layer can be calculated according to Equation (3). Figure 8 shows the relationship among the thickness, the porosity of the sand-fixing layer and the amount of the sprayed W-OH aqueous solution. The quantity of the material sprayed on the sand must not be too low; otherwise, the thickness of the sand-fixing layer will be too thin to achieve the purpose of sand fixation. When the amount of the sprayed W-OH aqueous solution is $3 \mathrm{~L} / \mathrm{m}^{2}$, the thickness of the sand-fixing layer is approximately $14 \mathrm{~mm}$, and the initial porosity is approximately $20 \%$. By increasing the amount, the thickness of the W-OH sand-fixing layer increases linearly; however, the initial porosity decreases due to the presence of more $\mathrm{W}-\mathrm{OH}$ aqueous solution and the shrinkage of the pore size, which increases the difficulty of penetration. Therefore, when the amount of the W-OH aqueous solution is $10 \mathrm{~L} / \mathrm{m}^{2}$, the thickness of the sandfixing layer is approximately $30 \mathrm{~mm}$, and the porosity decreases to $8 \%$. Considering the cost of desertification control and planting, the amount of $\mathrm{W}-\mathrm{OH}$ was usually set from $3 \mathrm{~L} / \mathrm{m}^{2}$ to $5 \mathrm{~L} / \mathrm{m}^{2}$.

$$
W \%=\frac{\frac{m_{1} \times w_{0} \%}{\rho_{1}}-\frac{m_{0}}{\rho_{0}}}{\frac{m_{1}}{\rho_{1}}} \times 100 \%
$$

where $m_{1}$ is the weight of the sand in the sand-fixing specimen, $\mathrm{g}$;

$w_{0} \%$ is the porosity of the shifting sand, which is

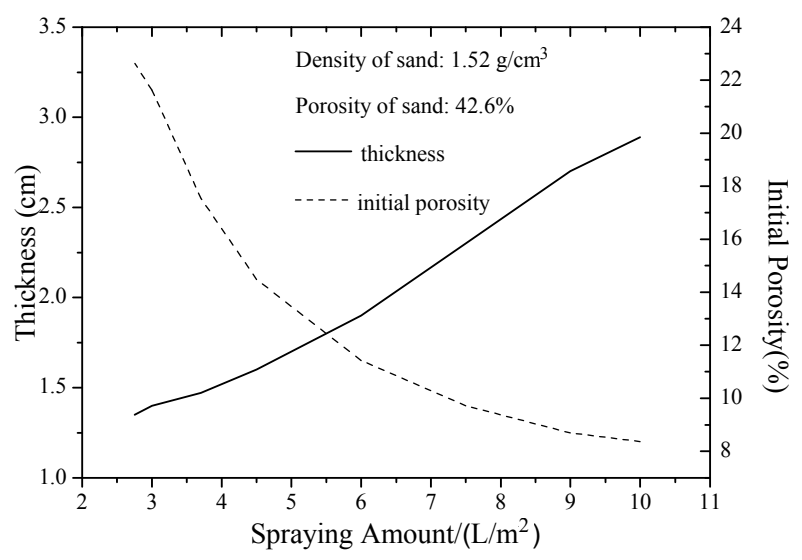

Figure 8. Relationship between thickness, initial porosity of the sand-fixing layer and spraying amount of $\mathrm{W}-\mathrm{OH}$ aqueous solution. 
$42.6 \%$ for the experiment;

$\rho_{1}$ is the density of the shifting sand, $\mathrm{g} / \mathrm{cm}^{3}$;

$m_{0}$ is the amount of the $\mathrm{W}-\mathrm{OH}$ aqueous solution sprayed on the sand-fixing specimen, $\mathrm{g}$;

$\rho_{0}$ is the density of the $\mathrm{W}-\mathrm{OH}$ aqueous solution, equal to water, $1 \mathrm{~g} / \mathrm{cm}^{3}$.

\subsection{Hardness and Compressive Stress of the W-OH Sand-Fixing Layer}

The excellent permeability of the W-OH aqueous solution guarantees that the sand-fixing layer has enough thickness and porosity. Hardness and compressive stress are important mechanical properties that reflect the stability of the fixed sand and the resistance to wind erosion.

Figure 9 shows the relationship between the hardness of the $\mathrm{W}-\mathrm{OH}$ sand-fixing specimens and the concentration of $\mathrm{W}-\mathrm{OH}$. W-OH can fix sand and advance the sand hardness, despite the loose sand with no hardness. When the sand was treated with a concentration of $3 \% \mathrm{~W}-\mathrm{OH}$ aqueous solution, the hardness was increased to $21 \mathrm{~mm}$. By increasing the concentration of the $\mathrm{W}-\mathrm{OH}$ aqueous solution, the polymerization degree and cross-linking degree of the $\mathrm{W}-\mathrm{OH}$ solid increase, and the force between the $\mathrm{W}-\mathrm{OH}$ solid and sand is increased. Moreover, the hardness of the sand-fixing specimens increases linearly with concentration of the $\mathrm{W}-\mathrm{OH}$ aqueous solution. Therefore, as the concentration of the $\mathrm{W}-\mathrm{OH}$ aqueous solution is increased to $7 \%$, the hardness of the layer reaches $28 \mathrm{~mm}$. The linear formula is shown in Equation (4), and $R^{2}$ is 0.99 .

$$
Y=1.6 X+16.7 \quad R^{2}=0.99
$$

where $Y$ is the hardness of the $\mathrm{W}-\mathrm{OH}$ sand-fixing specimen, mm;

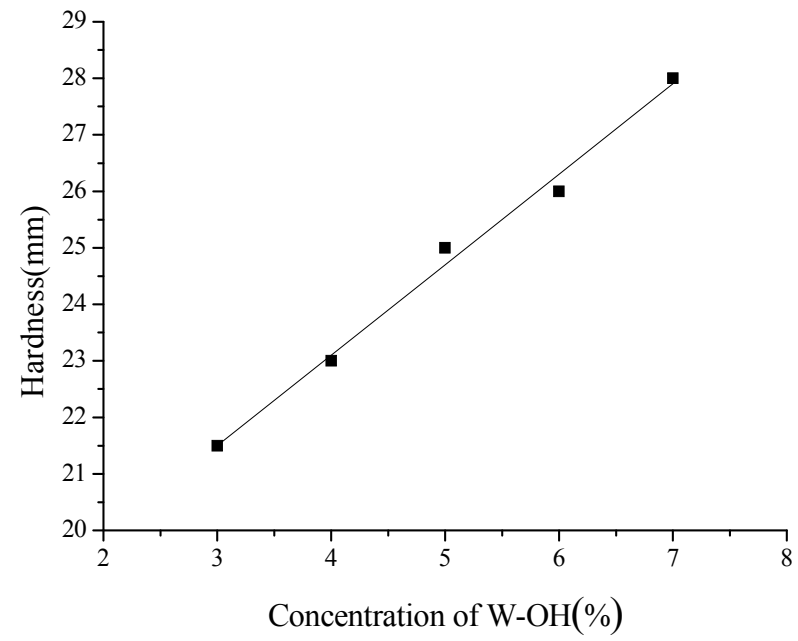

Figure 9. Relationship between the hardness of the sandfixing specimens and the concentration of $\mathrm{W}-\mathrm{OH}$.
$X$ is the concentration of $\mathrm{W}-\mathrm{OH}$ by weight percent, $\%$.

The relationship between the compressive stress of the sand-fixing specimens and the concentration of the $\mathrm{W}$ $\mathrm{OH}$ aqueous solution is shown in Figure 10. When the pressure was increased, the compressive horizontal/axial deformation of the sand-fixing specimen changed linearly. As the pressure achieved a certain value, the sandfixing specimen began to crack, and the pressure decreased gradually; thus, this value was the compressive stress of the $\mathrm{W}-\mathrm{OH}$ sand-fixing specimen. When the concentration of $\mathrm{W}-\mathrm{OH}$ was increased, the molecular weight of the $\mathrm{W}-\mathrm{OH}$ solid, the cross-linking density, the intensity, and the force between the solidification and sand particles were enhanced. Therefore, the compressive stress of the sand-fixing specimen was increased linearly by increasing the concentration of $\mathrm{W}-\mathrm{OH}$. As the concentration was increased from $3 \%$ to $7 \%$, the compressive strength was enhanced from $0.37 \mathrm{MPa}$ to $1.27 \mathrm{MPa}$. The linear formula is shown in Equation (5), and $R^{2}$ is 0.97 .

$$
Y=0.17576 X-0.22588 \quad R^{2}=0.97
$$

where $Y$ is the compressive stress of the $\mathrm{W}-\mathrm{OH}$ sandfixing specimens, $\mathrm{MPa}$;

$X$ is the concentration of $\mathrm{W}-\mathrm{OH}$ by weight percent, $\%$. Therefore, the sand treated by $\mathrm{W}-\mathrm{OH}$ has suitable mechanical properties to withstand strong wind speeds and adverse desert environments. However, the untreated sand can move and be blown away by the wind.

\subsection{Excellent Resistance to Wind Erosion}

The wind tunnel test was necessary to evaluate the active resistance to strong wind erosion of the $\mathrm{W}-\mathrm{OH}$ sandfixing layer. The amount of wind/sand erosion is defined as the weight reduction of sand by wind, and the wind erosion modulus is the amount of wind erosion per unit

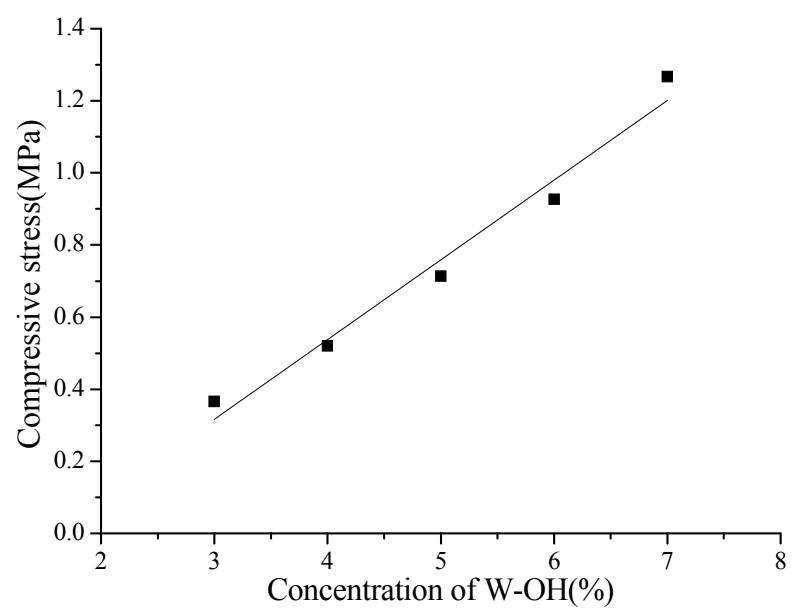

Figure 10. Relationship between the compressive stress of the sand-fixing specimens and the concentration of $\mathrm{W}-\mathrm{OH}$. 
area and unit time. They are important physical quantities for evaluating the resistance to wind erosion damage. The wind erosion modulus is calculated according to Equation (6).

$$
R_{e}=\left(m_{0}-m^{\prime}\right) / S \times T
$$

where $R_{e}$ is the wind erosion modulus, $\mathrm{g} \cdot \mathrm{m}^{-2} \cdot \mathrm{min}^{-1}$;

$m_{0}$ is the total mass of the sand specimen before testing, $\mathrm{g}$;

$m^{\prime}$ is the total mass of the specimen after testing, $\mathrm{g}$;

$S$ is the surface area of the specimen, $\mathrm{m}^{2}$; and

$T$ is the testing time, min.

The wind tunnel test results for the sand-fixing layer formed by a W-OH concentration of $2 \%$ are shown in Figure 11. The results demonstrate that a $\mathrm{W}-\mathrm{OH}$ concentration of $2 \%$ has a relatively poor resistance to wind erosion damage due to the weak solidification of the sand-fixing layer. The layer was damaged seriously during testing. When the wind-sand flow conditions were 10 $\mathrm{m} / \mathrm{s}$ and $0^{\circ}$, the wind erosion modulus was $0.0469 \mathrm{~g} / \mathrm{m}^{2} /$ min. With a stronger test wind and larger angle, the damage was more severe. Therefore, the corresponding wind erosion modulus was $1.3189 \mathrm{~g} / \mathrm{m}^{2} / \mathrm{min}$, under the action of a strong wind-sand flow with a velocity of 25 $\mathrm{m} / \mathrm{s}$ and a direction of $60^{\circ}$. Thus, this concentration is not suitable for application in desertification areas with strong winds.

Figure 12 shows the wind tunnel test results of the sand-fixing layer formed by a W-OH concentration of $3 \%$. It can be seen that the $\mathrm{W}-\mathrm{OH}$ concentration of $3 \%$ has a good resistance to wind erosion without any damage in the wind tunnel test. The greatest wind erosion modulus was $0.0783 \mathrm{~g} / \mathrm{m}^{2} / \mathrm{min}$, under the action of a strong wind-sand flow with a velocity of $25 \mathrm{~m} / \mathrm{s}$ and a direction of $60^{\circ}$, which is less than $1 / 15$ of that for the $2 \%$ concentration. It can thus be used in desertification areas with strong winds.

Tables 2 and 3 illustrate the wind tunnel test results for the $\mathrm{W}-\mathrm{OH}$ sand-fixing layers formed by concentrations of $4 \%$ and $5 \%$, respectively. The $\mathrm{W}-\mathrm{OH}$ sand-fixing

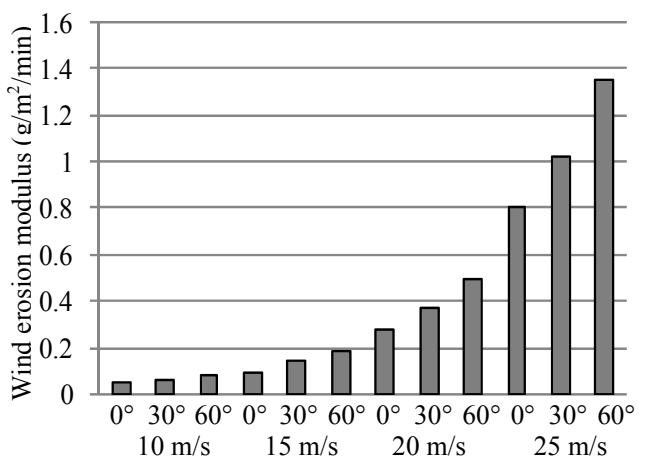

Figure 11. The wind tunnel test results of sand-fixing layer formed by a W-OH concentration of $2 \%$.

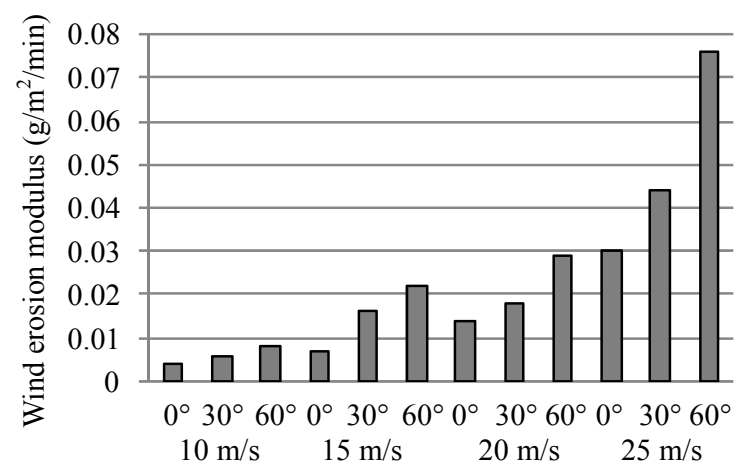

Figure 12. The wind tunnel test results of sand-fixing layer formed by a W-OH concentration of $3 \%$.

Table 2. The wind tunnel test results of sand-fixing layer formed by a W-OH concentration of $4 \%$.

\begin{tabular}{ccccc}
\hline $\begin{array}{c}\text { Wind } \\
\text { velocity } \\
(\mathrm{m} / \mathrm{s})\end{array}$ & $\begin{array}{c}\text { Testing } \\
\text { time } \\
(\mathrm{min})\end{array}$ & $\begin{array}{c}\text { Testing } \\
\text { angle }\left({ }^{\circ}\right)\end{array}$ & $\begin{array}{c}\text { Amount } \\
\text { of wind } \\
\text { erosion }(\mathrm{g})\end{array}$ & $\begin{array}{c}\text { Wind erosion } \\
\text { Modulus } \\
\left(\mathrm{g} / \mathrm{m}^{2} / \mathrm{min}\right)\end{array}$ \\
\hline \multirow{2}{*}{10} & 30 & 30 & 0 & 0 \\
& & 60 & 0 & 0 \\
15 & 20 & 0 & 0 & 0 \\
& & 30 & 0 & 0 \\
20 & 10 & 30 & -0.1697 & 0 \\
& & 60 & 0 & -0.0442 \\
& & 0 & -0.1825 & -0.1426 \\
25 & 8 & 30 & -0.1784 & -0.2805 \\
& & 60 & -0.3105 & -0.3032 \\
\hline
\end{tabular}

Table 3. The wind tunnel test results of sand-fixing layer formed by a W-OH concentration of $5 \%$.

\begin{tabular}{|c|c|c|c|c|}
\hline $\begin{array}{c}\text { Wind } \\
\text { velocity } \\
(\mathrm{m} / \mathrm{s})\end{array}$ & $\begin{array}{l}\text { Testing } \\
\text { time } \\
\text { (min) }\end{array}$ & $\begin{array}{c}\text { Testing } \\
\text { angle }\left({ }^{\circ}\right)\end{array}$ & $\begin{array}{c}\text { Amount } \\
\text { of wind } \\
\text { erosion }(g)\end{array}$ & $\begin{array}{l}\text { Wind erosion } \\
\text { modulus } \\
\left(\mathrm{g} / \mathrm{m}^{2} / \mathrm{min}\right)\end{array}$ \\
\hline \multirow{3}{*}{10} & \multirow{3}{*}{30} & 0 & 0 & 0 \\
\hline & & 30 & 0 & 0 \\
\hline & & 60 & 0 & 0 \\
\hline \multirow{3}{*}{15} & \multirow{3}{*}{20} & 0 & 0 & 0 \\
\hline & & 30 & 0 & 0 \\
\hline & & 60 & -0.19 & -0.0742 \\
\hline \multirow{3}{*}{20} & \multirow{3}{*}{10} & 0 & 0 & 0 \\
\hline & & 30 & -0.1652 & -0.1291 \\
\hline & & 60 & -0.4011 & -0.336 \\
\hline \multirow{3}{*}{25} & \multirow{3}{*}{8} & 0 & -0.0575 & -0.0562 \\
\hline & & 30 & -0.1938 & -0.1893 \\
\hline & & 60 & -0.3587 & -0.3503 \\
\hline
\end{tabular}


layers showed excellent resistance to wind erosion, and they were maintained well in a wind-sand flow with a velocity of $25 \mathrm{~m} / \mathrm{s}$ and a direction of $60^{\circ}$ without any damage. Some test specimens showed a weight increase during the wind tunnel test instead of a weight decrease, with a negative wind erosion modulus. For example, the wind erosion modulus was $-0.0442 \mathrm{~g} / \mathrm{m}^{2} / \mathrm{min}$ for a $4 \%$ $\mathrm{W}-\mathrm{OH}$ sand-fixing layer when the velocity of the windsand flow was $15 \mathrm{~m} / \mathrm{s}$ and the direction was $60^{\circ}$. This observation can be explained by the porous structure of the sand-fixing layer, which was filled with wind-blowing sand. As the wind-sand flow increased, more sand was blown into the pores, and the increase was larger. Accordingly, the weight of the wind erosion modulus was $-0.3503 \mathrm{~g} / \mathrm{m}^{2} / \mathrm{min}$ for a W-OH concentration of $5 \%$, under the action of a wind-sand flow with a velocity of $25 \mathrm{~m} / \mathrm{s}$ and a direction of $60^{\circ}$.

\section{Conclusion}

The $\mathrm{W}-\mathrm{OH}$ aqueous solution had excellent wettability on the surface of sand particles, and the adhesive force between $\mathrm{W}-\mathrm{OH}$ and sand was primarily through hydrogen bonds, covalent bonds and physical absorption, such as van der Waals forces. W-OH is a prepolymer of hydrophilic polyurethane containing -NCO, which can quickly react with $\mathrm{H}_{2} \mathrm{O}$ and other groups with active hydrogen. The $\mathrm{W}-\mathrm{OH}$ aqueous solution can solidify in the range from $13.8 \mathrm{~min}$ to $6 \mathrm{~min}$ for a concentration of $3 \%$, from $10 \mathrm{~min}$ to $4.3 \mathrm{~min}$ for a concentration of $4 \%$, from 5.6 min to $2.4 \mathrm{~min}$ for a concentration of $5 \%$, respectively, with an increase in the temperature from $5^{\circ} \mathrm{C}$ to $25^{\circ} \mathrm{C}$. Because of the low viscosity before solidification, the $\mathrm{W}-\mathrm{OH}$ aqueous solution can easily penetrate the sand, and a sand-fixing layer forms with a thickness of $8 \mathrm{~mm}$ $35 \mathrm{~mm}$ and a porosity of $25 \%-8 \%$ at a spraying concentration of $2 \mathrm{~L} / \mathrm{m}^{2}-10 \mathrm{~L} / \mathrm{m}^{2}$. The $\mathrm{W}-\mathrm{OH}$ sand-fixing layer was characterized by hardness in the range from $21 \mathrm{~mm}$ to $28 \mathrm{~mm}$ and compressive stress in the range from 0.37 $\mathrm{MPa} \mathrm{mm}$ to $1.27 \mathrm{MPa}$, respectively. When the concentration of $\mathrm{W}-\mathrm{OH}$ increased from $3 \%$ to $7 \%$, both of these mechanical properties increased linearly with W-OH concentration. Sand treated by $\mathrm{W}-\mathrm{OH}$ with a concentration greater than 3\% showed excellent resistance to strong wind erosion. It can withstand a wind velocity of $25 \mathrm{~m} / \mathrm{s}$ and a wind direction of $60^{\circ}$; however, sand treated by $\mathrm{W}-\mathrm{OH}$ with a concentration of $2 \%$ showed weak resistance to strong wind erosion with a large wind erosion modulus of $1.3189 \mathrm{~g} \cdot \mathrm{m}^{-2} \cdot \mathrm{min}^{-1}$ by a velocity of $25 \mathrm{~m} / \mathrm{s}$ of wind. Therefore, $\mathrm{W}-\mathrm{OH}$ is an excellent sand-fixing material, and it provides a promising solution for desert control.

\section{Acknowledgements}

This work was financial supported by the Japanese New the China-Japan Cooperation Projects of International Science and Technology (2010DFB54170), and the National Key Technology R\&D Program of the 12th fiveyear plan (2012BAC09B05).

\section{REFERENCES}

[1] UNEP, "United Nations Convention to Combat Desertification," UNEP, Nairobi, 1994, p. 35.

[2] J. Jian, H. J. Li and X. A. Dai, "Research on Land Sandy Desertification Using Remote Sensing Taking Qinghai Lake Area as an Example," Geo-Information Science, Vol. 8, No. 2, 2006, pp. 116-120.

[3] L. L. Wang, Z. Y. Qin and N. S. Qin, "Climate Change and Its Impact on Desertification around Qinghai Lake," Plateau Meteorology, Vol. 21, No. 1, 2002, pp. 59-65.

[4] M. V. Lopez, M. Sabre, R. Gracia, J. L. Arrue and L. Gomes, "Tillage Effects on Soil Surface Conditions and Dust Emission by Wind Erosion in Semiarid Aragon (NE Spain)," Soil and Tillage Research, Vol. 45, No. 1-2, 1998, pp. 91-105. doi:10.1016/S0167-1987(97)00066-4

[5] A. Kade and S. D. Warren, "Soil and Plant Recovery after Historic Military Disturbance in the Sonoran Desert USA," Arid Land Research and Management, Vol. 16, No. 3, 2002, pp. 231-243. doi:10.1080/153249802760284784

[6] G. Dirk and Y. O. Zvi, “Aeolian Dust Erosion on Different Types of Hills in a Rocky Desert: Wind Tunnel Simulations and Field Measurements," Journal of Arid Environments, Vol. 37, No. 2, 1997, pp. 209-229. doi:10.1006/jare.1997.0282

[7] K. Michels, M. V. Sivakumar and B. E. Allison, "Wind Erosion Control Using Crop Residue. Effects on Soil Flux and Soil Properties," Field Crops Research, Vol. 40, No. 2, 1995, pp. 101-110. doi:10.1016/0378-4290(94)00094-S

[8] T. Wang, "Remote Sensing Monitoring and Assessing Sandy Desertification: An Example from the Sandy Desertification Region of Northern China," Quaternary Sciences, Vol. 2, 1998, pp. 108-118.

[9] T. H. Zhang, H. L. Zhao, S. G. Li, F. R. Li, Y. Shirato, T. Ohkuro and I. Taniyama, "A Comparison of Different Measures for Stabilizing Moving Sand Dunes in the Horqin Sandy Land of Inner Mongolia, China," Journal of Arid Environments, Vol. 58, No. 2, 2004, pp. 203-214.

[10] F. R. Li, L. F. Kang, H. Zhang, L. Y. Zhao, Y. Shirato and I. Taniyama, "Changes in Intensity of Wind Erosion at Different Stages of Degradation Development in Grasslands of Inner Mongolia, China," Journal of Arid Environments, Vol. 62, No. 4, 2005, pp. 567-585. doi:10.1016/j.jaridenv.2005.01.014

[11] Z. B. Dong, G. T. Chen, X. D. He, Z. W. Han and X. M. Wang, "Controlling Blown Sand along the Highway Crossing the Taklimakan Desert," Journal of Arid Environments, Vol. 57, No. 3, 2004, pp. 329-344. doi:10.1016/j.jaridenv.2002.02.001

[12] J. Ren, L. Tao and X. M. Liu, "Effect of Different Microhabitats and Stand Age on Survival of Introduced Sand-Fixing Plants," Journal of Arid Environments, Vol. 51, No. 3, 2002, pp. 413-421. doi:10.1006/jare.2001.0967 
[13] FUJIYOSITAKAO, "Integrated Areas to Prevent the Desertification, Chemistry and Industry," Chemical Society of Japan, Vol. 61, No. 2, 2008, pp. 103-107.

[14] J. Yang, F. Wang, L. Fang and T. W. Tan, "Synthesis, Characterization and Application of a Novel Chemical Sand Fixing Agent-Poly (Aspartic Acid) and Its Composites," Environmental Pollution, Vol. 149, No. 1, 2007, pp. 125-130. doi:10.1016/j.envpol.2006.12.021

[15] R. A. Siddiqi and C. J. Moore, "Polymer Stabilization of Sandy Soils for Erosion Control," Transportation Research Record, No. 827, 1981, pp. 30-34.

[16] M. L. Shawqui and A. Neaz, "Effect of New Soil Stabilizers on the Compressive Strength of Dune Sand," Construction and Agents, Vol. 12, No. 6-7, 1998, pp. 321328.

[17] Z. Dong, L. Wang and S. Zhao, "A Potential Compound for Sand Fixation Synthesized from the Effluent of Pulp and Paper Mills," Journal of Arid Environments, Vol. 72, No. 7, 2008, pp. 1388-1393. doi:10.1016/i.jaridenv.2008.02.008

[18] Z. S. Wu, Z. R. Wu, K. Iwashita and H. Inagaki, "Development of Sand Stabilization and Greening Technique with Osrganic Slurry Containing Hydrophilic Polyurethane," The 4th International Workshop for R\&D Clustering among China, Japan, Korea in Eco-Materials Processing (CJK 2008)(Keynote), Hakone, 2008.
[19] Z. R. Wu, K. Iwashita, Z. S. Wu and H. Inagaki, "Research on Sand Dune Fixation and Green Vegetation of a Novel Chemical Material and Construction Method of Demonstration Areas around Qinghai Lake," The Report of METI NEDO Project, H19 NO. 0710002.

[20] Z. R. Wu, K. Iwashita, Z. S. Wu and H. Inagaki, "Experimental Study on Evaluation and Control of Ultraviolet Resistance of Sand Stabilized with Organic Slurry Containing Hydrophilic Polyurethane," Journal of the Japan Society of Material Science, Vol. 57, No. 11, 2008, pp. 1167-1172. doi:10.2472/jsms.57.1167

[21] Z. R. Wu, Z. S. Wu, K. Iwashita, W. M. Gao and H. Inagaki, "UV Irradiation Degradation Control of Sand Stabilized with Organic Slurry Containing Hydrophilic Polyurethane," Journal of the Japan Society of Material Science, Vol. 60, No. 3, 2011, pp. 235-239. doi: $10.2472 /$ jsms. 60.235

[22] Y. M. Wang, W. W. Chen and W. F. Han, "Simulation Study on Resistances to Wind Erosion of New Polymer Material in Sand Fixation," Journal of Soil and Water Conservation, Vol. 19, No. 6, 2005, pp. 12-14.

[23] Q. C. Chen, P. F. Jiang and T. W. Lei, "Wind Tunnel Experiment on the Impacts of Polyacrylamide on Wind Erosion of Loosen Soil Materials," Transactions of the CSAE, Vol. 22, No. 10, 2006, pp. 7-11 